\title{
MISCELANEA
}

\section{LA MÍMESIS CONCEPTISTA DE OVANDO Y SANTARÉN}

\author{
Antonio Carreira
}

Al Festin de las musas y noches de Apolo (Málaga, 1950) asistieron escasos invitados, cincuenta exactamente, suscriptores de la colección "A quien conmigo va". Su anfitrión, el poeta Juan de Ovando y Santarén (1624-1706), de quien se imprimió otro opúsculo también minoritario en 1965, siguió siendo un ilustre desconocido hasta hoy que sale su obra mayor, en edición dirigida a un público más amplio *. No se trata de fingir alborozo por la aparición de un libro indispensable y largamente esperado. De hecho, sin la poesía de Ovando puede muy bien pasar quien no tenga curiosidad por Málaga y sus glorias locales. Pero Ovando, que a pesar de su humanismo tardío y de sus andanzas napolitanas se muestra ante todo ferviente cantor de su patria chica, manifiesta asimismo un entusiasmo algo ingenuo por la milicia (en la que fue capitán), la orden de Calatrava, Nuestra Señora de la Victoria y la economía doméstica, que lo hace representativo de la visión conformista complementaria de la escéptica y picaril en una época agobiada bajo el peso de la grandeza pretérita y de la nulidad presente.

Todo ello queda claro en la introducción de C. Cuevas, enriquecida con datos del manuscrito Muñoz Rojas. En la constelación familiar del poeta brillan caballeros bien situados en diversos puestos militares y administrativos, que por activa o por pasiva se relacionan con las musas. El mismo lleva una vida típica de hidalgo acomodado en la que no faltan la épica juvenil - su intervención para sofocar la revuelta del populo en 1648- y los escarceos eróticos - un hijo natural diez años más tarde-, hasta que con el matrimonio sienta cabeza y se integra en la rutina ciudadana portando

* Juan de Ovando y Santarén: Ocios de Castalia en diversos poemas. Edición, introducción y notas de Cristóbal Cuevas. Textos latinos, Francisco Talavera. Málaga: Diputación Provincial, 1987; 543 págs. 
estandartes, participando en justas y haciendo a la vez cuentas y poemas: " janás estuvieron las musas tan cerca de la bolsa, ni la lírica de los pucheros" (pág. 36). También ayuda como puede en la epidemia de 1678, en el terremoto de $1680 \mathrm{y}$ en el bombardeo de 1693, mientras alterna viajes a Madrid con venturas y desventuras de su vida privada: enviuda en 1664, contrae nuevas nupcias en 1670, y atiende por igual a casar bien sus hijas -que pronto le dan nietos-, defender la Concepción de la Virgen y redactar las constituciones de su cofradía. Tales actividades repercuten naturalmente en sus poemas, que no encuentran grandes asuntos de que ocuparse hasta 1682, cuando los ejércitos imperiales se enfrentan al turco. Pulsa entonces la lira guerrera y compone su Orfeo militar (1688), respuesta a una pastoral del obispo fray Alonso de Santo Tomás, en opinión de C. C. Aparte este libro y los Ocios de Castalia (1663), no sabemos, porque el editor no lo dice, si los Villancicos (1681) y los Afectos contritos de un soldado en la hora de la muerte (posteriores a 1697) son o no obras extensas e importantes. Tampoco tenemos más noticia de sus comedias que la dada por J. A. Muñoz Rojas y A. Canales en su edic. del Festín..., págs. 26-29.

La segunda parte del prólogo estudia la poesía de Ovando, presentándola como paradigma del barroco, sea cual fuere el sentido que pueda conservar término tan sobado. Las razones de esta clasificación son múltiples: Ovando establece la variedad como base de su estética (pág. 44); pasa de la imitatio renacentista a la inventio barroca (pág. 45 ; luego veremos eso); extrae lecciones morales de la belleza efímera (pág. 49); asume "la barroca concepción del mundo como teatro" (pág. 52), si bien "curiosamente... no recurre al gran símbolo barroco de la vida como sueño" (pág. 53). En un momento dado Cuevas llega a atribuirle angustia (pág. 52). Para sustentar sus argumentos remite a trabajos de D'Ors, Hatzfeld, Wellek y Orozco sobre el concepto de barroco. Wellek, sin embargo, en su viejo artículo (ampliado en 1963) ya subrayaba el malentendido que había en la apreciación de la poesía "barroca" durante el expresionismo (es decir, cuando el término se difunde) y exponía sus recelos ante un estilo capaz de agrupar desde Rabelais y Guevara hasta Racine y Calderón, al tiempo que ironizaba sobre la creencia de Hatzfeld en el "básico y eterno" barroco español, o la de Eugenio d'Ors, que veía barroco en todas partes, desde el siglo xv en Portugal hasta el XIX con Wagner en Alemania: "It would, however, be foolish to expect a single noun or adjective such as baroque to carry unimpeded and still clearly realized a dozen different connotations" (Concepts of Criticism, New Haven, 1963, pág. 93). Por lo que respecta a los escritores supuestamente barrocos aficionados a la metáfora y demás recursos conceptistas, esta es la conclusión del mismo autor: "The figures and metaphors, hyperboles and catachreses frequently do not reveal any inner ten- 
sion or turbulence and may not be the expression of any vital experience (Erlebnis) at all, but may be the decorative overelaborations of a highly conscious, sceptical craftsman, the pilings-up of calculated surprises and effects" (op. cit., pág. 111).

En efecto, este es a nuestro juicio el caso de Ovando: el mismo Cuevas dice más adelante que en la raíz de su poesía amorosa "hay más literatura que sentimientos personales" (pág. 56), que en ese tema es "poeta de mímesis" (no de inventio, pág. 57), y que en el religioso puede considerarse "típico ejemplar del católico español postridentino" (pág. 53); sus sátiras están "lejos de la amargura deformante del autor de los Sueños" (pág. 60), su oscuridad es calculada (pág. 61), y posee una "enorme capacidad idealizadora, pues frente a los ejércitos españoles de entonces, llenos de pencos malmontados por jinetes famélicos y sin pertrechos -a veces por pícaros como Estebanillo González, su contemporáneo estricto ${ }^{1-}$, nuestro poeta forja un mundo militar idealizado, en el que hasta los enemigos están llenos de grandeza" (págs. 47-48). Las Erlebnisse de hombre semejante, ciudadano honorable y virtuoso padre de familia, que habia hecho donación de su alma a la Virgen por escritura pública, que fundaba capillas y que veía milagros en sus propios tropiezos (pág. 374), no eran como para producir angustia, sino todo lo más insomnio ( $y$ a él parecen aludir tres de sus poemas nocturnos, págs. 151, 153 y 402). Si ello configura o no una personalidad barroca, júzguelo el discreto lector. Pero antes vea ciertas vacilaciones del propio Cuevas, cuyo estudio por lo demás es excelente: "tras la huella de Garcilaso y los renacentistas, [Ovando] canta a la naturaleza y al paisaje. Su detallismo, su sentido de lo bello, su colorismo y su sinceridad le acercan a la escuela antequerano-granadina" (pág. 57), aunque es de las Soledades de donde toma "el sentido de una Naturaleza protagonística, cuya descripción se convierte en objetivo estético primordial" (pág. 74). "El barroquismo de Ovando se manifiesta especialmente en su sistemática búsqueda de la forma perfecta" (pág. 60), acreditada por las abundantes correcciones de sus autógrafos (pág. 61), pero esa búsqueda lo acerca al muy clásico Herrera (pág. 64). En resumen, Ovando es poeta de variadas lecturas e influencias: "ni culterano ni conceptista en exclusiva, mezcla sabiamente recursos de ambas procedencias, demostrando que se trata de corrientes no antitéticas sino complementarias" (pág. 79), y así su poesía es "culteranoconceptista" (págs. 79-80). La solución, por baciyélmica que parezca, se acerca bastante a la verdad y no solo respecto a Ovando, sino a la mayoria

\footnotetext{
1 Y su estricto paisano, si lo identificamos con el autor de la obra descubierto por Jesús A. Cid. Cf. "Máscaras y oficio en un escritor del antiguo régimen: Estebanillo González $\propto$ Gabriel de la Vega", RDTP, XLIII (1988), págs. 175-195.
} 
de los poetas de su tiempo, Góngora incluido, y se deja entender mucho más univocamente que el comodín del barroco.

Dejando a un lado la introducción, atinada y documentada cuanto se quiere, echemos un vistazo a los Ocios de Castalia. Señala Cuevas que se trata de un libro organizado por su autor con arreglo a "criterios métricos, combinados con aspectos temáticos y de lengua" (pág. 50) e impreso bajo su vigilancia - hecho infrecuente en la lírica áurea. Por ello se respeta su ortografía, resolviendo abreviaturas y modernizando la puntuación. El texto e ilustraciones de obra tan voluminosa se han reproducido con esmero ejemplar: hay huellas de una insistente corrección de pruebas y todo denota una lectura atenta al ritmo y al sentido del verso, aunque en las notas el editor peca más bien por defecto ${ }^{2}$. La poesía de Ovando no es muy difícil, y cuando lo son ocasionales pasajes, suelen aclararse oportunamente. Queda sin embargo bastante por hacer; el lector común a buen seguro hubiera preferido encontrar resueltas frases y alusiones problemáticas antes que envíos a raros libros neolatinos: hallar o coger a uno en mal latín (pág. 112), ir con letura (pág. 118), quedar el brazo sano (pág. 119), cantar como alemanes (pág. 122), echar de la gloriosa (pág. 165), llevar cola (pág. 194), marearse la fruta u otra cosa (pág. 210), saltar por el rey de Francia (pág. 299), “a más no poder acuéstase Pedro con su mujer" (pág. 351), chillar la potra (pág. 386), son algunas de las frases hechas que, aparte su sentido más o menos obvio, convendría identificar como tales. Términos propios o apelativos como Pulla (pág. 197), maravilla (pág. 205), Moscobia (pág. 212), Mandricardo (rey de los tártaros en el Orlando furioso, pág. 286), cavallos (página 29.7), habas (pág. 314), limpios (pág. 331), país, rimas (pág. 443), Calisto (pág. 445), entre otros, no son de los que esclarecen los diccionarios. Menos aún la anécdota de Cleopatra y Marco Antonio (pág. 323) o la de los chirlos mirlos (pág. 211 ; cf. Correas, Vocabulario, ed. Combet, 553b).

2 Las erratas son tan escasas que no vale la pena indicarlas. Hay, en cambio, algunas palabras no explicadas que lo parecen: zarmines (pág. 222), ajusto (pág. 241), taramas (pág. 333), grípolas (que será grímpolas, pág. 450). Faltan signos de interrogación en la primera quintilla de pág. 315 , y sobran en pág. 336, v. 153. Los lapsus también son raros: un par de ellos lingüísticos ("en base a estos actos de heroísmo", pág. 27, y "apadrinar lo que naçiesse de pila”, pág. 38), carentes de importancia en una prosa siempre docta y amena. Otros igualmente leves ocurren en las notas: página 402, núm. 1-2, Faetonte no cayó en el mar; pág. 419, núm. 164, Hades no es hijo de Estige; pág. 434, núm. 31, Hipocrene no es Castalia; la primera estaba, como Aganipe, en el Helicón (Beocia), mientras que la segunda en el Parnaso (Fócide); pág. 469, núm. 899, Lilibeo no es el Etna sino el promontorio situado al otro extremo de Sicilia. La nota de pág. 363 probablemente va descaminada: el poema que celebra la fábula de Píramo y Tisbe "por la agudeza de un autor moderno" no ha de referirse a la de Góngora sino a otra más reciente como la de Miguel de Efrén y Quevedo, impresa en Málaga por Juan Serrano de Vargas en 1656 (Gallardo, II, 810). Cf. Andrés Llordén, La imprenta en Málaga, I (Málaga, 1973), pág. 49. 
Hay por último un aspecto vagamente atendido en esta edición que requiere tratamiento más ininucioso. Cuevas declara con razón epigonales los versos de Ovando (pág. 60), pero después de detectar en ellos las influencias más visibles, deja a nuestro cuidado el rastrear otras, cosa que en su opinión puede hacerse "sin demasiado esfuerzo" (pág. 73). Fácil o difícil, esa tarea es muy necesaria. La poesía de Ocios tiende modestamente al tono menor, temas y formas son los de siempre, sin perjuicio de tímidos experimentos métricos (destacados por Cuevas en pág. 66). Ovando no aparta sus ojos de los grandes maestros, cuyos recursos ensarta una y otra vez en busca de novedad combinatoria. Acude al bazar del conceptismo y, aturdido por variedad tan relumbrante, carga con lo que puede y lo vuelca en poemas que no tienen de suyo más que el haberle costado su dinero. Esto no le ocurre solo a él, sino a la mayor parte de sus colegas, con los que habría habido que relacionarlo y autorizarlo precisando los distintos grados de la imitatio, desde la más descarada de Trillo y Figueroa y la muy graciosa de Solís, hasta la de quienes se ríen de sus andadores como Cornejo y Polo de Medina, o pretenden caminar sin ellos, como el Conde de Rebolledo ${ }^{3}$. Ovando incorpora a su obra la complicidad del lector, obligado a reconocer los modelos cercanos o lejanos para no atribuir al microtexto origen y sentido erróneos. No es el mismo caso de Góngora, que hace alusiones a clásicos griegos y latinos, a romances viejos, refranes y consejas, en la seguridad de que la diferencia respecto de su engaste puede suplir su localización. Las citas de Ovando se acercan más al funcionamiento de la parodia -en el mismo Góngora o en otros-, donde la identificación es imprescindible. Cuando en el Orfeo militar, 2. a parte, empieza una elegia latina con el verso In nova fert animus versas memorare phalanges, el lector debe percibir que el primer hemistiquio pertenece al hexámetro inicial de las Metamorfosis; como debe recordar el comienzo del Panegírico gongorino ("Si arrebatado merecí algún día / tu dictamen ...") al abrir el Festin de las musas: "Si en éxtasis canoro remontado / ... influirme ... / he merecido", pues Góngora y Ovidio son para Ovando dechados igualmente remotos y admirables. En Ocios de Castalia los ecos son incesantes y contribuyen a la textura tanto como las voces: "Esta del Paro hermosa pesadumbre", pág. 132, es reminiscencia de

3 Por ejemplo, el soneto "Tú que en cortes de Flora presumida”, pág. 146, cabe enfrentarlo al de Solís "Viene abril y ¿qué hace? En dos razones", mucho más audaz y desmitificador. En el romance "De aquel belicoso apóstol", pág. 174, sería útil remitir a los cuatro poemas de Bocángel al mismo asunto. El romance "En estatua has de salir", pág. 216, se puede relacionar con el vejamen a Judas de Damián Cornejo (ed. Pörtl, München: Wilhelm Fink, 1978, págs. 109 y 143). El romance “Dios en Belén se hace hombre", pág. 499, muestra del peor conceptismo sacro, tiene también paralelo en el dedicado al Nacimiento por el P. Cornejo (ed. cit., pág. 196), con citas de lugares madrileños y castellanos. 
Garcilaso, Égloga III 211. La silepsis de villano y cruzado, pág. 250, remite a "Hero y Leandro en paños menores" de Quevedo (ed. Blecua, núm. 771), vv. 105-108. El floreo verbal con Guisa, pág. 255, está ya en el romance gongorino de Rengifo (ed. Millé, núm. 73), así como el juego con peto y espaldar de pág. 242. La broma con Vegecio, pág. 271, proviene de las décimas de Coridón (Millé, 157), donde significan lo mismo. La sátira a los médicos cuya sortija pronostica la losa, pág. 318, es puro Quevedo (Blecua, 544). La antítesis soplar/inspirar, pág. 341, confiere buena parte de su malicia a la primera de las décimas contra Quevedo que se atribuyen a Góngora (Millé, XXII). "A promesas galalones / doy respuestas durandartes", pág. 361, apunta al romance "Al tronco de un verde mirto" también de Góngora (Millé, 81), donde se lee: "esperanzas Bradamantes / entre cuidados Rugeros". Los versos "quando haziendo un ruyseñor / cátedra de un olmo inculto", pág. 389, mezclan lugares de la Tisbe, como el resto del romance, de igual asonancia; más claro aún se ve en "Ruiseñor divino entonces", pág. 391, calco de "orador Píramo entonces", v. 269 de la fábula. La imagen de un bajel como ave de presa, pág. 392, es también de linaje gongorino: cf. el romance "Según vuelan por el agua" (Millé, 49). Poco después, en el mismo poema, "de la salobre campaña / era galería inculta" un escollo -que tiene precedente en las Soledades: "imperioso mira la canpaña / un escollo, apacible galería ..." (I, 186-187). El "violín de pluma" de pág. 409 se ha escapado de la letrilla "No son todos ruiseñores" (Millé, 145), y el "clarín del albor con alas", pág. 410, suena ya en el romance "Contando estaban sus rayos" (Millé, 72), mientras que la imagen de los ramos como atril o facistol del pájaro (págs. 404, 410) es creación quevedesca (Blecua, 206). Las "intempestivas tollinas" de pág. 448 son los "intempestivos atunes" de la $2 .^{a}$ Soledad, vv. 414-416, y por alli se encuentran también la tortuga que nada inmóvil largos siglos, pág. 481, las nudosas invenciones de las redes y tantas cosas más. Otros muchos ecos, aunque debilitados, podrían captarse en los retruécanos con nombres de calles (páginas 122, 136, 274), títulos nobiliarios (págs. 172, 261, 379, 499), apellidos (pág. 249), juegos de cartas (págs. 194, 208, 213, 257, 290), telas (págs. 420, 446), romancero (págs. 255, 269, 498), así como en los temas: sátiras a cornudos (págs. 142, 305, 306, 349), flacas (págs. 228, 301, 349), viejas (página 269), pidonas (págs. 295, 359), terceras (págs. 313, 341), diversos oficios (pág. 339; cf. Quevedo, ed. Blecua, 542), un capón (pág. 344), una roma (pág. 350), pasteleros (pág. 355), afeites (págs. 364, 366), etc. Mayor entidad tienen las citas : sendas cuartetas de romances adaptan otra de Hurtado de Mendoza : 
Compitiendo con los remos quando los silbos madrugan, confiesso que ya sus manos forman abriles de espuma.

(pág. 293)
Compitiendo con las selvas donde las flores madrugan los pájaros en el viento forman abriles de espuma.

(A. de Mendoza, ed. Benítez Claros, I, 196).

Compitiendo con las selvas quando madrugan al alba los pájaros en el viento dan las giradas.

(pág. 384)

El romance "Estaba satisfaciendo / a su marido Catalna", pág. 263, toma los personajes, el lenguaje y el v. 34 de la "Pendencia mosquito" de Quevedo (Blecua, 861); de ella y el "Desafío de dos jaques" (Blecua, 858) procede la jácara "Dándole el pecho a las chicas", pág. 332. Mismo abolengo quevedesco ostentan las composiciones de págs. 228, 241, 243, 269, 272, 278,285 y 317 . Pero la palma de las citas corresponde, claro, a Góngora : el soneto "Formaba de una quinta en campo hermoso", pág. 142, es un interesante caso de trasposición de una isotopía palaciega desde el romance "Esperando están la rosa" (Millé, 61) a otra bélica. Por cierto que el último verso, donde aparece la paronomasia mosqueta / mosquete(ría), asímismo gongorina (Millé, 150), ha dejado huella en Adriano del Valle, según Dámaso Alonso (Arpa fiel, 3. ${ }^{\text {a }}$ edic., Madricl, 1942, págs. 22 y 96). El soneto "Muros de yedra y fuentes de zafiro", pág. 144, se inspira en idéntico romance de Góngora con algún toque del soneto "Lazos de plata y de esmeralda rizos" de Lope de Vega (Rimas... de Burguillos, 1634, 27v) en los cuartetos. Y aún hay otro poema en pág. 383 derivado del romance en cuestión, que Ovando debía de saber de memoria. El romance "Píntase el poeta a sí mismo", pág. 170, no depende de Cervantes, como anota Cuevas, sino del autorretrato de don Luis "Hanme dicho, hermanas" (Millé, 24), igualmente célebre. El soneto de pág. 156 que "cuenta las fiestas que en Granada se hizieron tres días" no recuerda tanto el citado en nota (Millé, 280) como el atribuido "Bien dispuesta madera en nueva traza" (Millé, XLV), que clescribe un auto de fe celebrado hacia 1615 precisamente en Vivarrambla: basta leer el verso 14 de ambas composiciones o el adjetivo desgranado que les es común aplicado al público. "Por los relinchos, lozano / y por las cernejas, fuerte", pág. 179, es cita textual del romance "Entre los sueltos ca ballos" (Millé, 17) y suscita eco en vv. 307-8 del poema: "por lo torzido. vinagres / y por lo alcuças, azeites", pág. 184. Otro fragmento elabora algo más la referencia: "Al cristal de Guadiana / Ayamonte lo confiesse, / sus 
torres antiguas donde / ciñe esclarecidamente", págs. 179-180. Góngora lo había dicho al revés : "Donde esclarecidamente / guarnecen antiguas torres / el cristal del Oceano / en que se mira Ayamonte" (Millé, 57). El v. 62 ("ardientes suspiros lanza") del romance "De Riarán en la isla", pág. 285, es el v. 23 de "Entre los sueltos caballos" acabado de mencionar. Los vv. 79-80 ("engendradoras de sierpes / de aquestas arenas hija") del romance al ruiseñor, pág. 411, copian otros dos del mismo sitio ("hija al fin de estas arenas / engendradoras de sierpes", Millé, 17). La diaporesis de pág. 416, "aplicando al hombro el arco / Venus se duda o Cupido", sale del canto de Polifemo, estrofa LVIII. El romance "Tu estancia, Fuente la Teja", pág. 494, embebe dos versos de "Cloris el más bello grano" (Millé, 66) :

\section{Ovando}

de essa Granada a quien lame Genil, galán de los ríos.

\section{Góngora}

de la Granada a quien lame sus cáscaras el Genil.

El soneto "Poca amistad y muchos allegados", pág. 141, no tiene por modelo el gongorino "Grandes más que elefantes y que abadas" (Millé, 252), sino otro anónimo, indistintamente atribuido a Góngora y a Villamediana: "Poca justicia, muchos alguaciles" (cf. la edic. de B. Ciplijauskaité, Madison, 1981, págs. 653-4), contaminado con aquel. El siguiente de tema similar, "Lindos sitios y buenos mentideros", pág. 145, mucho mejor, sigue de cerca al de Góngora, que también deja trazas en la descripción de Nápoles de pág. 157. En cuanto a dos versos entrecomillados en una décima de pág. 357, "Francelisa, cuyos ojos / mi culpa y disculpa son", pertenecen a uno de los pocos romances de Villamediana, el que comienza "Para qué es, Amor tirano", publicado en sus Obras (Zaragoza: Juan de Lanaja, 1629), pág. 347b. Francelisa en este caso no es personaje del romancero, como dice la nota, sino la reina (francesa) Isabel de Borbón, esposa de Felipe IV. Así le llama también el Conde en los tercetos "¿Quién le concederá a mi fantasía ?", v. 41, añadidos en la 3.2 edición de sus Obras (Madrid: María de Quiñones, 1635), pág. 413.

¿Qué quedará de Ovando una vez completo el inventario de su guardarropía? Bastante sin duda, y no necesariamente lo mejor, ya que es en la imitación donde se encuentra como el pez en el agua. Hay, sí, algunas octavas valientes en el Orfeo militar, otras valiosas en el Festín de las musas... En Ocios de Castalia, los conceptos aplicados a la poesía latina, el color local en la "Descripción panegírica de Málaga", con sus etimologías prosaicas y sus bimembres cerrando estrofa. Del resto, algunos versos logrados ("y las hojas que caen con tono triste", pág. 149; "La idea de mi locura / con plumas de pensamientos / se atrevió a surcar los vientos / por esferas de 
hermosura", pág. 371), y esa querencia malagueña aludida al principio, que le hace cantar el mar cambiante ("lo que fue rizo azul ya es fondo en raso", pág. 446), el cielo despejado ("nunca su cielo el fúnebre texido / que nuves traman por el ayre, obtiene", pág. 440), las naves del puerto (que "como en golfos mareadas vienen, / echan del cuerpo quanto dentro tienen", dice con ocurrencia algo chabacana, pág. 450), y los crepúsculos, morosamente saboreados (págs. 379, 392, 398):

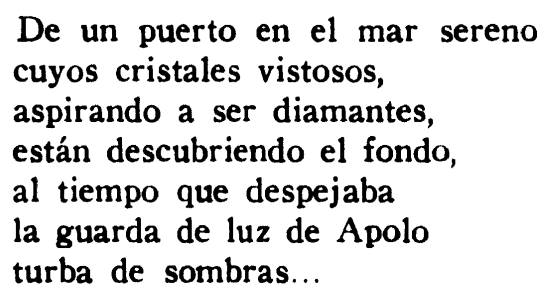

Tal es el escenario del romance "a Lisi, que se bañó en el mar" (página 382) sin saber que su galán la contemplaba desde la barca:

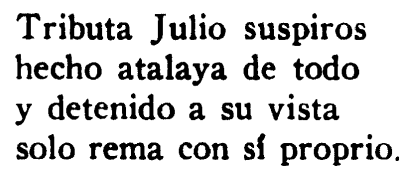

En todo esto, si se quiere, es posible incluso ver prefigurada la poesía temprana de otro malagueño crepuscular de nuestros días, Emilio Prados *

- Como este poemilla de Tiempo (Málaga, 1925), pág. 18: "Duerme la calma en el puerto / bajo su colcha de laca / mientras la luna en el cielo / clava su dorada ancla. / Corazón, / rema". 